\title{
Adherence to Medication, Physical Activity and Diet in Older Adults With Diabetes: Its Association With Cognition, Anxiety and Depression
}

\author{
Rosa Mendes $^{\mathrm{a}, \mathrm{b}, \mathrm{e}}$, Sonia Martins ${ }^{\mathrm{b}, \mathrm{c}}$, Lia Fernandes ${ }^{\mathrm{b}, \mathrm{c}, \mathrm{d}}$
}

\begin{abstract}
Background: Adherence to medication, physical activity (PA) and diet in diabetes mellitus (DM) patients is crucial for its good management, avoiding acute and chronic complications. There are several risk factors associated with non-adherence, including cognitive impairment, depression and anxiety. Nevertheless, studies on therapeutic adherence in older patients with DM are scarce. In this context, the present study aimed to analyze whether adherence to medication, PA and diet are associated with cognitive impairment, anxiety and depression. It also aimed to identity predictors of medication non-adherence.

Methods: A cross-sectional study of older patients ( $\geq 65$ years old) with DM was carried out in the Outpatient Department of Internal Medicine Service of CHUSJ-Porto, Portugal. Those unable to communicate were excluded. Cognition (mini-mental state examination), anxiety and depression (hospital anxiety and depression scale) were assessed. Adherence to medication, PA and diet was measured, based on self-reporting patient/family, questionnaires, physician clinical opinion, hemoglobin test and pharmacy records. Patient groups were compared, using the Mann-Whitney or the Kruskal-Wallis test for continuous variables and the Chi-square test for paired categorical variables (significance level of 0.05 ). The odds ratio (OR) was calculated to identify independent predictors of non-adherence to medication.
\end{abstract}

Results: The final sample $(n=94)$ had a mean age of 75.2 years (standard deviation: 6.7) and mostly were female (53.2\%), married $(63.8 \%)$ and with a low education level (61.7\%). Also, $22.3 \%$ with

Manuscript submitted May 31, 2019, accepted June 20, 2019

aDepartment of Internal Medicine, Centro Hospitalar Universitario S. Joao (CHUSJ), Porto, Portugal

${ }^{\mathrm{b}}$ Center for Health Technology and Services Research (CINTESIS), Faculty of Medicine, University of Porto (FMUP), Portugal

'Department of Clinical Neurosciences and Mental Health, Faculty of Medicine, University of Porto (FMUP), Portugal

${ }^{\mathrm{d} C l i n i c}$ of Psychiatry and Mental Health, Centro Hospitalar Universitario S. Joao (CHUSJ), Porto, Portugal

${ }^{\mathrm{e} C}$ Corresponding Author: Rosa Mendes, Department of Internal Medicine, Centro Hospitalar Universitario S. Joao (CHUSJ), Alameda Prof. Hernani Monteiro, 4200-319 Porto, Portugal.

Email: rosammendes59@gmail.com

doi: https://doi.org/10.14740/jocmr3894 cognitive impairment, $16 \%$ with depression and $23.4 \%$ with anxiety were found. Patients non-adherent to medication had higher depression $(\mathrm{P}=0.048)$ and anxiety $(\mathrm{P}=0.010)$, compared to adherents/ partial adherents. Patients non-adherent to PA showed higher anxiety $(\mathrm{P}=0.035)$ and depression $(\mathrm{P}=0.004)$, compared to adherents. Non-adherents to PA had more cognitive impairment than adherents ( $26.3 \%$ vs. $0 \%$; $\mathrm{P}=0.034)$. Patients who had insulin prescribed presented a higher risk of non-adherence to medication (OR: 4.041, 95\% confidence interval $(\mathrm{CI}): 1.404-11.628 ; \mathrm{P}=0.010)$. Also, the risk of non-adherence to medication is higher by an increase of one unit in anxiety (OR: $1.252,95 \% \mathrm{CI}: 1.046-1.499 ; \mathrm{P}=0.014$ ).

Conclusions: Higher anxiety and depression were associated with non-adherence to medication and to PA. Insulin prescribed and high anxiety scores were predictors of medication non-adherence. This study appears to contribute to the knowledge about the influence of cognitive and psychological factors in therapeutic adherence in these older diabetic patients.

Keywords: Aging; Diabetes mellitus; Therapeutic adherence; Cognitive impairment; Anxiety; Depression

\section{Introduction}

With an aging population worldwide between 2015 and 2050, the proportion of older persons will have risen from $15 \%$ today to $22 \%$ in 2050 [1], contributing to the increase of the prevalence of chronic diseases [2-4], also known as non-communicable diseases (NCDs). The main types of NCDs are cardiovascular diseases (e.g. heart attacks and strokes), cancer, chronic respiratory diseases (such as asthma and chronic obstructive respiratory disease) and diabetes, accounting for over $80 \%$ of all premature NCDs deaths [5].

Diabetes mellitus (DM) is a chronic pandemic disease affecting about 422 million people worldwide, and its prevalence will double in the next 20 years [6]. DM prevalence is estimated to be $22-33 \%$ in older people [7-9]. The type $2 \mathrm{DM}$ (formerly called non-insulin-dependent or with adult-onset) results from the body's ineffective use of insulin and is one of the most common chronic conditions among older people. The treatment of type $2 \mathrm{DM}$ involves a healthy diet and physical activity (PA) along with control of blood glucose levels and 
a complex therapeutic regimen (oral hypoglycemic drugs and insulin therapy) and also management of risk factors that can contribute to the damage of blood vessels [10].

In older adults, in addition to the macro- and microvascular complications of DM, the association with other chronic diseases and geriatric syndromes (cognitive impairment, depression, urinary incontinence, falling and polypharmacy) makes the individual's functional status very heterogeneous, so that it becomes more difficult to treat these patients [11]. Besides that, this treatment should be individualized and flexible, taking into account comorbid diseases and their physical, cognitive and social needs [12].

$\mathrm{DM}$ is one of the pathologies in which therapeutic adherence is crucial for the good management of this disease, in order to avoid both acute and chronic complications [13].

Therapeutic adherence is defined by the World Health Organization (WHO) as "the extent to which a person's behavior - taking medication, following a diet, and/or executing lifestyle changes, corresponds with agreed recommendations from a healthcare provider" [14], considering this a primary factor for good chronic disease management.

Nevertheless, among older adults, the prevalence of therapeutic non-adherence is as high as 50\% [15-19]. Furthermore, about $20 \%$ of these cases have prescribed medications, which they do not take [20].

Non-adherence has significant consequences for diabetes outcomes and the effectiveness of treatment. Particularly, several studies have reported this non-adherence to treatment, associated with an increase in mortality and hospitalization rates, resulting in higher healthcare expenses [21].

Evidence suggests that several risk factors are implicated in this therapeutic non-adherence, including sociodemographic characteristics (e.g. old age, male gender, low education and financial circumstances), physical and mental health (e.g. cognitive impairment, functional dependency, depression, anxiety), medication factors (e.g. complexity and multiple prescriptions, high costs) and factors related to the health care system (e.g. pharmacy accessibility, absence of follow-up) [22-28].

Concerning mental health, DM has been associated with an increased risk of psychiatric disorders, with particular emphasis on depression and anxiety [15]. In patients with DM compared with non-diabetic, the prevalence of depression doubles and up to $30 \%$ of diabetics have depressive symptoms, with more prolonged and recurrent episodes [29-32].

Depression has also been associated with worse self-care and therapeutic adherence, which could explain its relation to negative outcomes in DM $[33,34]$, such as poor quality of life, increase of healthcare service use [35], risk of complications [34] and death [36, 37].

The symptoms of depression that may cause the most interference include fatigue, loss of motivation and hopelessness [38].

In a meta-analysis study, the authors demonstrated a significant association between depression and non-adherence treatment in patients with DM, suggesting that depression may exacerbate this, since patients may have little interest in following therapeutic plans, may be more isolated and have low social network and family support [39-41].

Anxiety is another common mental disorder found in patients with DM. Some studies have shown that anxiety prev- alence is twice as high in diabetic patients as in the general population [42-43], increasing in older adult patients [44].

The presence of marked anxiety symptoms may lead to non-adherence [45], in spite of this association not being completely clear and some studies presenting contradictory results, which may be explained by this anxiety symptoms heterogeneity $[46,47,48]$.

Cognitive impairment is another important factor related to therapeutic non-adherence. In diabetic patients, this prevalence is higher than in non-diabetic persons [49, 50]. Several studies point to DM (particularly type 2) being associated with an increased risk of cognitive impairment and even dementia [51, 52].

Cognitive dysfunction is of particular relevance in this context, because of its impact on diabetes self-care. Diabetes patients must be able to motorize glucose level, take medications and/or insulin injections and follow a diet and exercise plan. They also need to recognize, treat and prevent complications (e.g. hypoglycemia), and know how to react when ill. Performing models of care for diabetic foot and dental care, as well as attending medical appointments, may be other complex tasks involved in DM management $[53,54]$.

Bearing this in mind, patients with memory loss may double medication doses or forget to take it, forget insulin injections and to monitor blood glucose, as well as to eat on time. When executive functions, such as judgment, problem-solving, starting new behaviors, or stopping old behaviors are compromised, the patient may have difficulty in adapting to complex therapeutic regimens or new therapy, and change their routines [55-59].

Studies on the therapeutic adherence in older adult patients, with DM are scarce. Bearing this in mind, the present study aimed to analyze whether adherence to medication, PA and diet are associated with cognitive impairment and psychological factors (anxiety and depression) in DM older patients. This work also aimed to identity predictors of non-adherence to medication in these patients.

\section{Materials and Methods}

\section{Sample}

A cross-sectional study was carried out with older adult outpatients from the Internal Medicine Department of the Centro Hospitalar Universitario Sao Joao (CHUSJ), in Porto, Portugal. The following inclusion criteria were considered: 1) aged $\geq 65$ years old and 2) diagnosis of diabetes, according to the American Diabetes Association [60] (fasting glucose plasma $\geq$ $126 \mathrm{mg} / \mathrm{dL}(7.0 \mathrm{mmol} / \mathrm{L})$, or 2 -h plasma glucose $(\mathrm{PG}) \geq 200$ $\mathrm{mg} / \mathrm{dL}(11.1 \mathrm{mmol} / \mathrm{L})$ during an oral glucose tolerance test (OGTT) or $\mathrm{A} 1 \mathrm{C} \geq 6.5 \%(48 \mathrm{mmol} / \mathrm{mol})$, or in a patient with classic symptoms of hyperglycemia or hyperglycemic crisis, a random plasma glucose $\geq 200 \mathrm{mg} / \mathrm{dL}(11.1 \mathrm{mmol} / \mathrm{L})$ ). Patients were excluded if they were unable to communicate.

\section{Procedures}

All eligible patients were screened by the researcher at a 
medical appointment. At the study enrolment, after informed consent, older adult patients were assessed with a research protocol, which includes a socio-demographic and clinical interview, as well as cognitive global and psychological measures. Complete socio-demographic characteristics of patients, including Graffar index (GI) [61, 62], and clinical parameters, such as body mass index (BMI) and Charlson comorbidity index (CCI) [63], comorbidities, medication and glycated hemoglobin levels were obtained through chart review, hospital records and clinical interview.

\section{Measures}

All participants included were assessed with the following instruments.

\section{GI}

The GI is an international classification, established by Graffar [61], based on five criteria: education, occupation, income, household and neighborhood characteristics, to define the socio-economic status (SES). The sum of the scores in each one of the five criteria indicates the socio-economic class: I - upper class (5 - 9 points), II - upper-middle (10 - 13 points), III middle (14 - 17 points), IV - low-middle (18 - 21 points) and $\mathrm{V}$ - low (22 - 25 points) [62].

\section{$B M I$}

The BMI was calculated using the following formula: $\mathrm{BMI}=$ weight $(\mathrm{kg}) /$ height $(\mathrm{m})^{2}$. Normal weight $(\mathrm{BMI}=18.50$ 24.99), overweight (BMI = 25.00 - 29.99) and obese categories $(\mathrm{BMI}>30)$ were considered [64].

\section{Cognition assessment: mini-mental state examination (MMSE)}

The MMSE is the most widely used brief screening instrument for assessing cognitive mental status. It evaluates five areas of cognitive function, including orientation, memory, attention/ calculation, language and visual construction. The total score ranges from 0 (impaired) to 30 (normal) [64]. In the present study, the Portuguese normative values were used, with the following interpretation to possible cognitive decline if MMSE $\leq$ 22 for subjects from 0 to 2 years of education, $\leq 24$ for subjects with 3 - 6 years of education and $\leq 27$ for those with $\geq 7$ years of education $[65,66]$.

Psychological measure: hospital anxiety and depression scale (HADS)

The HADS was developed by Zigmond and Snaith [67] as a practical tool to assess anxiety and depressive symptoms in a general medical population. The HADS contains 14 items and consists of two subscales: anxiety (HADS-A) and depression (HADS-D). Each item is rated on a four-point Likert scale (range $0-3$ ). The total score is the sum of the 14 items, and for each subscale, the score is the sum of the respective seven items (ranging from 0 to 21 ). In the present study, the Portuguese version of HADS was used [68] and the following cut-off points were considered on either subscale: 0 - 7 (normal), 8 - 10 (mild), 11 - 14 (moderate) and 15 - 21 (severe).

\section{Adherence to medication, $P A$ and diet}

Medication adherence was assessed based on the following measures: self-reporting accomplishment by the patient, using also the measure treatment adherence (MTA) scale [69], hemoglobin levels and physician clinical opinion, as well as confirmation of withdrawal of prescribed medication from the pharmacy records. Based on this information, patients were classified in one of the following three groups: non-adherent, partially adherent and adherent.

Regular PA was defined as the performance of at least one activity, such as walking, water aerobics and cycling, between 2 and 3 times per week, according to the American Diabetes Association and the American College of Sports Medicine guidelines $[10,70,71]$. Adherence to PA was defined as a dichotomized variable for analysis.

Adherence to diet was considered if the patient fulfilled the previously defined food plan, and was assessed in a clinical interview by patient self-reporting, corroborated by the information from the family and/or caregiver. All patients were categorized as adherent, partially adherent or non-adherent.

\section{Ethical considerations}

This study was conducted in accordance with the ethical principles of the Declaration of Helsinki, and was approved by the Ethics Committee for Health at the Hospital (CHUSJ) where the study took place. Written informed consent of all study participants was obtained at enrolment in the study. For patients who were not capable of providing consent (e.g. dementia), consent of a close relative or proxy consent was obtained.

\section{Statistical analysis}

Patient characteristics were presented as raw frequencies and percentages for categorical variables, as median and range for continuous variables if normality was not assumed, or as mean and standard deviation (SD) if normality was assumed.

Differences between non-adherent, partially adherent and adherent to medication were tested using Kruskal-Wallis test for continuous variables.

Scores in HADS and in MMSE were compared between patients who were adherent and those who were non-adherent to PA and to diet (this last variable was recoded in dichoto- 
Table 1. Socio-Demographic and Clinical Characteristics of the Sample

\begin{tabular}{ll}
\hline Age (years), mean (SD) & $75.2(6.7)$ \\
Education (years), mean (SD) & $3.3(2.0)$ \\
Gender, n (\%) & \\
$\quad$ Male & $44(46.8)$ \\
$\quad$ Female & $50(53.2)$ \\
Marital status, n (\%) & $3(3.2)$ \\
$\quad$ Single & $60(63.8)$ \\
$\quad$ Married & $2(2.1)$ \\
$\quad$ Divorced/separated & $29(30.9)$ \\
Widowed & $19(20.2)$ \\
Living situation, n (\%) & $61(64.9)$ \\
Alone & $12(12.8)$ \\
With partner & $2(2.1)$ \\
With son or daughter & \\
\hline With another relative & $22(23.4)$ \\
\hline Has a carer?, n (\%) & $72(76.6)$ \\
\hline No & \\
Yes & \\
\hline
\end{tabular}

mous: adherent/partially adherent vs. non-adherent), using the Mann-Whitney test for continuous variables and the Chisquare test for paired categorical variables.

Odds ratio (OR) and its $95 \%$ confidence interval (CI) were calculated to identify independent predictors of non-adherence to medication recoded in non-adherent/partially adherent vs. adherent. Variables associated with this outcome with a P-value $<0.05$ in the univariate analyses and variables considered clinically significant were included (method ENTER) into a multiple logistic regression model for non-adherence to medication in order to identify independent risk factors.

The significance level used was 0.05 . The statistical analyses were performed using the Statistical Package for the Social Sciences Version 24.0 for Windows software (SPSS).

\section{Results}

\section{Socio-demographic and clinical characteristics of the sam- ple}

The final sample included 94 patients, with a mean age of 75.2 years (SD: 6.7). They were mostly female (53.2\%), married $(63.8 \%)$ and with a mean education of 3.3 years (SD: 2$)$. The majority lived with their partner $(64.9 \%)$ and had a family caregiver $(76.6 \%)$ (Table 1). Concerning socio-economic class, patients were grouped in class III (middle: 14 - 17 points), class IV (low-middle: 18 - 21 points) and class $\mathrm{V}$ (low: 22 - 25 points).

Regarding clinical characteristics, the majority of the patients were in overweight (39.4\%) and in obese (38.3\%)
Table 2. Clinical Characteristics of Sample

\begin{tabular}{|c|c|}
\hline \multicolumn{2}{|l|}{ BMI, n (\%) } \\
\hline Normal weight & $21(22.3)$ \\
\hline Overweight & $37(39.4)$ \\
\hline Obese & $36(38.3)$ \\
\hline CCI, mean (SD) & $2.4(1.3)$ \\
\hline Total of comorbidities, mean (SD) & $5.9(1.7)$ \\
\hline Medication (daily), mean (SD) & $8.8(2.3)$ \\
\hline \multicolumn{2}{|l|}{ Adherence to medication, $\mathrm{n}(\%)$} \\
\hline Non-adherent & $14(14.9)$ \\
\hline Partially adherent & $14(14.9)$ \\
\hline Adherent & $66(70.2)$ \\
\hline \multicolumn{2}{|l|}{ Adherence to PA, n (\%) } \\
\hline Non-adherent & $80(85.1)$ \\
\hline Adherent & $14(14.9)$ \\
\hline \multicolumn{2}{|l|}{ Adherence to diet, $\mathrm{n}(\%)$} \\
\hline Non-adherent & $59(62.8)$ \\
\hline Adherent & $35(37.2)$ \\
\hline \multicolumn{2}{|l|}{ Cognitive impairment, $\mathrm{n}(\%)$} \\
\hline Without cognitive impairment & $73(77.7)$ \\
\hline With cognitive impairment & $21(22.3)$ \\
\hline \multicolumn{2}{|l|}{ Depression, n (\%) } \\
\hline Without depression & $79(84.0)$ \\
\hline With depression & $15(16.0)$ \\
\hline \multicolumn{2}{|l|}{ Anxiety, n (\%) } \\
\hline Without anxiety & $72(76.6)$ \\
\hline With anxiety & $22(23.4)$ \\
\hline
\end{tabular}

BMI: body mass index; CCI: Charlson comorbidity index; SD: standard deviation; PA: physical activity.

categories, according to their BMI. The sample had on average 5.9 (SD: 1.7) comorbidities and major polypharmacy (defined as five or more medicines) was frequently observed $(98.9 \%)$. The number of medicines taken was 8.8 (SD: 2.3 ) on average.

Concerning medication adherence, almost $30 \%$ of patients were non- or partially adherent. Most of the patients were nonadherent to PA (85.1\%) and to diet $(62.8 \%)$.

According to MMSE assessment, $22.3 \%$ had cognitive impairment. Related to psychological variables, $16 \%$ of patients presented depression and $23.4 \%$ anxiety, based on HADS scores.

Detailed clinical characteristics of these patients are presented in Table 2.

\section{Association between adherence and cognitive impairment}

In this study, non-adherents to PA had more cognitive impairment than adherents $(26.3 \%$ vs. $0 \% ; \mathrm{P}=0.034)$. 
Table 3. Therapeutic Adherence, Anxiety and Depression

\begin{tabular}{|c|c|c|c|c|}
\hline & \multicolumn{4}{|c|}{ HADS (total scores) } \\
\hline & Anxiety, median (min. - max.) & P-value & Depression, median (min. - max.) & P-value \\
\hline \multicolumn{5}{|l|}{ Adherence to medication } \\
\hline Partially adherent & $6(1-10)$ & & $3(1-9)$ & \\
\hline Adherent & $4(0-13)$ & & $2(0-19)$ & \\
\hline Non-adherent & $4(0-17)$ & 0.035 & $3(0-19)$ & 0.004 \\
\hline Adherent & $2(1-10)$ & & $1(0-10)$ & \\
\hline \multicolumn{5}{|l|}{ Adherence to diet } \\
\hline Non-adherent & $4(0-17)$ & 0.637 & $3(0-19)$ & 0.243 \\
\hline Adherent & $4(1-13)$ & & $2(0-12)$ & \\
\hline
\end{tabular}

Adherence to medication was analyzed with Kruskal-Wallis test, whereas adherence to PA or diet was analyzed with Mann-Whitney test. HADS: hospital anxiety and depression scale; PA: physical activity.

No differences were found in total MMSE scores (cognition) between groups of patients, concerning medication and diet adherence.

\section{Association between adherence, depression and anxiety}

With regard to medication adherence, significant differences between the three groups were found in anxiety $(\mathrm{P}=0.010)$ and in depression $(\mathrm{P}=0.048)$ scores, both being higher among the non-adherent patient group, compared to the adherent and to the partially adherent groups. Comparing the two groups of non-adherent and adherent to PA, the first one presented higher anxiety $(P=0.035)$ and depression scores $(P=0.004)$. No significant differences were found between groups regarding adherence to diet (Table 3).

\section{Predictors of non-adherence to medication}

In the univariate analyses, no significant differences between the two groups (non/partially adherent vs. adherent) were found, in relation to socio-demographic variables (age, gender, marital status, living situation, career, socio-economic class) and clinical variables (total number of daily medication, total of comorbidities, CCI and BMI), with the exception of insulin prescription. In this way, in the non-adherent/partially adherent patients group, $73.3 \%$ were prescribed insulin, while in the adherent group only $42.2 \%$ had an insulin prescription $(\mathrm{P}=0.005)$.

After these analyses, a multiple logistic regression model was carried out, in order to identify independent predictors of non-adherence to medication. This model included variables associated with this outcome (depression, anxiety, insulin prescription) in univariate analysis, as well as other characteristics considered clinically significant (age and gender). From the analysis of this model (Table 4), it was possible to verify that patients who had insulin prescribed presented a higher risk of non-adherence to medication (OR: 4.041, 95\%
CI: $1.404-11.628, \mathrm{P}=0.010$ ). In addition, by an increase of one unit in anxiety score, the risk of non-adherence to medication will rise (OR: $1.252,95 \% \mathrm{CI}$ : $1.046-1.499, \mathrm{P}$ $=0.014)$.

\section{Discussion}

Depression and anxiety are common psychiatric disorders in older people with DM, confirmed by some studies with a prevalence of $25 \%$ for depression and $40.3 \%$ for anxiety [ 31 , 72-74]. In the present study, $16 \%$ of the older patients had depressive symptoms and $23.4 \%$ had anxiety symptoms. These values, although clinically significant, are lower than those found in the literature $[31,72,73]$, which may be due to the fact that this sample includes patients with few complications associated with DM, an important contributory factor for the increase in these psychiatric manifestations [75].

There are many other factors, that may contribute to these high rates, such as a change in lifestyle, adaptation to treatment, fear of negative impact of chronic and acute complications [76-78], as well as the perception of greater dependence caused by DM [79].

The presence of these psychiatric disorders can interfere with the management of DM by influencing treatment adher-

Table 4. Predictors of Non-adherence to Medication

\begin{tabular}{lll}
\hline & OR $(\mathbf{9 5 \%}$ CI) & P value \\
\hline Age & $1.010(0.934-1.093)$ & 0.802 \\
Gender (female) & $0.926(0.329-2.611)$ & 0.885 \\
Anxiety (total HADS-A) & $1.252(1.046-1.499)$ & $0.014^{*}$ \\
Depression (total HADS-D) & $0.984(0.850-1.139)$ & 0.827 \\
Insulin prescription (yes) & $4.041(1.404-11.628)$ & $0.010^{*}$ \\
\hline
\end{tabular}

${ }^{*} \mathrm{P}<0.05$. OR: odds ratio; $\mathrm{Cl}$ : confidence interval. HADS: hospital anxiety and depression scale. 
ence [80-83]. In this study, the patients' non-adherence to medication presented higher levels of depression and anxiety, compared to adherents and partial adherents. Some authors [25, 30] suggested that diabetics with depression may have more difficulty in dealing with the daily changes needed for good management of this disease, particularly with the medication intake [25], which may result in poorer glucose control and more complications [30].

On the other hand, poor metabolic control could increase depressive symptoms, further reducing the ability to correctly manage DM [84]. Besides, poor metabolic control may lead to complications, which may be associated with worsening depression $[30,33,85]$.

To evaluate the factors directly affecting non-adherence to medication, a multiple logistic regression model was performed. Initial analyses of the multiple logistic regression model included not only variables previously associated with non-adherence to medication, but also other characteristics considered clinically significant (e.g. medication, comorbidity). Nevertheless, since the results were similar either with or without the inclusion of these characteristics, the most simplified final model was considered in this study, which included the variables: age, gender, insulin prescription, anxiety and depression.

Based on this model, patients who had insulin prescribed, presented a higher risk of non-adherence to medication. This may be explained by insulin intake being usually a more complex therapeutic regime that requires greater capacity and commitment in the management of the disease, as well as greater family/social support. Other reasons have been mentioned by some studies, such as the fear of the risks of taking insulin, fear of hypoglycemia, negative social impact and the perception that the use of insulin will be an incapacity/failure to efficiently manage this disease $[13,86]$.

From the multiple logistic regression model, it was also possible to verify that high anxiety scores were predictors of non-adherence to medication. Previous studies have found that approximately $60 \%$ of patients with DM reported anxiety associated with the daily management of the disease, namely due to the significant modifications required by this illness (e.g. changes in diet, complex medication regimens, smoking cessation and glycemic control). The presence of anxiety has been related to non-adherence to medication, as well as to uncontrolled diabetes, and consequently to the increase of related complications [54, 87-92].

Some authors [93-95] suggested that the effects of anxiety on medication adherence may be mediated by the patient's self-efficacy expectation (i.e. perception of his/her capacity to carry out a specific task). In this way, patients with low selfefficacy expectation make less effort in taking medicines as prescribed, and are also more likely to maximize the severity of obstacles to treatment adherence. This may lead to inefficacious thinking, impairment of functioning and low medication adherence. Also, patients with anxiety may have low coping mechanisms, using specific coping styles, such as avoidance, escape and denial, which have been associated with reduced adherence to diabetes self-care regimens and poorer glycemic control [88, 96-100].

Regarding PA adherence, it is known that PA is important in preventing DM onset $[101,102]$ and also in metabolic control [103]. However, some studies have shown that DM patients take less regular exercise, compared to non-diabetics [35]. Also, it was found that only one-third of DM patients do regular exercise while one-third are sedentary [104, 105]. In older people with DM, the percentages are even lower [106], as can be seen in the present study, in which only $15 \%$ of the sample practiced regular PA.

There are several factors that can contribute to this nonadherence, such as the presence of anxiety, depression and cognitive impairment. In the current work, non-adherents to PA revealed more anxiety and depression compared to adherents. Also, non-adherents to PA had more cognitive impairment than adherents. Actually, patients with cognitive impairment have less autonomy, as well as less ability to perceive the benefits of PA. In this way, it would be important to involve the caregivers in this process, because family support is crucial to PA adherence [107].

Considering the few studies in older people with DM, the present research appears as an important contribution to the knowledge about the factors related to the adherence to medication, physical exercise and diet in this age group. In addition, this work also contributes to the characterization of essential clinical variables in older DM patients, such as depression, anxiety and cognitive impairment.

The limitations of this study are related to the cross-sectional design and to the fact that it was carried out only on one site (an outpatient setting). Thus, the results may not be generalizable to patients cared for in other settings.

Future studies are needed to overcome these limitations and to deepen this area of research, namely including other potential risk factors associated with therapeutic non-adherence in older DM patients. Also, future longitudinal studies will be required, in order to clarify the effect of treating anxiety and depression on the improvement in adherence.

In conclusion, the present findings suggest that early detection and management of anxiety, depression and cognitive impairment could be used to improve patients' engagement with medication and PA, contributing also to prevention and better management of this disease.

Also, the commitment of these patients in the decisionmaking to the treatment plan is crucial, focusing on the need for psycho-educational interventions in order to motivate and involve them and their caregivers.

\section{Acknowledgments}

The authors wish to thank all patients for their collaboration.

\section{Financial Disclosure}

None.

\section{Conflict of Interest}

The authors declare no conflict of interest. 


\section{Informed Consent}

Written informed consent was obtained from all patients.

\section{Author Contributions}

Rosa Mendes, Sonia Martins and Lia Fernandes participated in the conception and design of the study. Rosa Mendes, Sonia Martins and Lia Fernandes contributed to the writing of the article, analyses and interpretation of the results, as well as to the critical revision of the article. Rosa Mendes participated in the data collection. All authors have approved the final manuscript.

\section{References}

1. World Health Organization (WHO). Ageing and health Key Facts. Available at: http://www.who.int/news-room/ fact-sheets/detail/ageing-and-health. Accessed January 2019.

2. Hopman WM, Harrison MB, Coo H, Friedberg E, Buchanan M, VanDenKerkhof EG. Associations between chronic disease, age and physical and mental health status. Chronic Dis Can. 2009;29(3):108-116.

3. Jacob L, Breuer J, Kostev K. Prevalence of chronic diseases among older patients in German general practices. Ger Med Sci. 2016;14:Doc03.

4. World Health Organization (WHO). Non communicable diseases. Fact sheet. Updated June 2018. Available at: https://www.who.int/news-room/fact-sheets/detail/noncommunicable-diseases. Accessed January 2019.

5. World Health Organization (WHO) Deaths from NCDs. Available at: https://www.who.int/gho/ncd/mortality morbidity/ncd total_text/en/ Accessed January 2019.

6. International Diabetes Federation (IDF). Recommendations for managing type 2 diabetes in primary care. 2017. Available at: www.idf.org/managing-type2-diabetes.

7. Centers for Disease Control and Prevention. National diabetes fact sheet: national estimates and general information on diabetes and prediabetes in the United States, 2011. Atlanta, GA: US department of health and human services, centers for disease control and prevention. 2011;201(1):2568-2569.

8. Cowie CC, Rust KF, Ford ES, Eberhardt MS, Byrd-Holt DD, Li C, Williams DE, et al. Full accounting of diabetes and pre-diabetes in the U.S. population in 1988-1994 and 2005-2006. Diabetes Care. 2009;32(2):287-294.

9. Dankner R, Geulayov G, Olmer L, Kaplan G. Undetected type 2 diabetes in older adults. Age Ageing. 2009;38(1):56-62.

10. American Diabetes Association. 4. Lifestyle Management: Standards of Medical Care in Diabetes-2018. Diabetes Care. 2018;41(Suppl 1):S38-S50.

11. Corriere M, Rooparinesingh N, Kalyani RR. Epidemiology of diabetes and diabetes complications in the elderly: an emerging public health burden. Curr Diab Rep.
2013;13(6):805-813.

12. American Diabetes Association. 11. Older Adults: Standards of Medical Care in Diabetes-2018. Diabetes Care. 2018;41(Suppl 1):S119-S125.

13. Garcia-Perez LE, Alvarez M, Dilla T, Gil-Guillen V, Orozco-Beltran D. Adherence to therapies in patients with type 2 diabetes. Diabetes Ther. 2013;4(2):175-194.

14. De Geest S, Sabate E. Adherence to long-term therapies: evidence for action. Eur J Cardiovasc Nurs. 2003;2(4):323.

15. Morris LS, Schulz RM. Patient compliance - an overview. J Clin Pharm Ther. 1992;17(5):283-295.

16. Lassen LC. Patient compliance in general practice. Scand J Prim Health Care. 1989;7(3):179-180.

17. Jin H, Kim Y, Rhie SJ. Factors affecting medication adherence in elderly people. Patient Prefer Adherence. 2016;10:2117-2125.

18. Blackburn DF, Swidrovich J, Lemstra M. Non-adherence in type 2 diabetes: practical considerations for interpreting the literature. Patient Prefer Adherence. 2013;7:183189.

19. McElnay JC, McCallion CR, al-Deagi F, Scott M. Selfreported medication non-compliance in the elderly. Eur J Clin Pharmacol. 1997;53(3-4):171-178.

20. Pereira Monterroso LE, Joaquim N, Sa LO. Medication adherence in elderly people integrated in the Long-Term Care domiciliary teams. Revista de Enfermagem Referência. 2015;(5):9-16.

21. Ernst FR, Grizzle AJ. Drug-related morbidity and mortality: updating the cost-of-illness model. J Am Pharm Assoc (Wash). 2001;41(2):192-199.

22. van Dulmen S, Sluijs E, van Dijk L, de Ridder D, Heerdink R, Bensing J. Patient adherence to medical treatment: a review of reviews. BMC Health Serv Res. 2007;7:55.

23. Capoccia K, Odegard PS, Letassy N. Medication Adherence With Diabetes Medication: A Systematic Review of the Literature. Diabetes Educ. 2016;42(1):34-71.

24. Donovan JL. Patient decision making. The missing ingredient in compliance research. Int J Technol Assess Health Care. 1995;11(3):443-455.

25. Al-Hayek AA, Robert AA, Alzaid AA, Nusair HM, Zbaidi NS, Al-Eithan MH, Sam AE. Association between diabetes self-care, medication adherence, anxiety, depression, and glycemic control in type 2 diabetes. Saudi Med J. 2012;33(6):681-683.

26. Klein DN, Shankman SA, Rose S. Ten-year prospective follow-up study of the naturalistic course of dysthymic disorder and double depression. Am J Psychiatry. 2006;163(5):872-880.

27. Licht-Strunk E, van der Windt DA, van Marwijk HW, de Haan M, Beekman AT. The prognosis of depression in older patients in general practice and the community. A systematic review. Fam Pract. 2007;24(2):168-180.

28. Cole MG, Bellavance F, Mansour A. Prognosis of depression in elderly community and primary care populations: a systematic review and meta-analysis. Am J Psychiatry. 1999;156(8):1182-1189.

29. Anderson RJ, Freedland KE, Clouse RE, Lustman PJ. The prevalence of comorbid depression in adults with di- 
abetes: a meta-analysis. Diabetes Care. 2001;24(6):10691078.

30. Roy T, Lloyd CE. Epidemiology of depression and diabetes: a systematic review. J Affect Disord. 2012;142(Suppl):S8-21.

31. Ali S, Stone MA, Peters JL, Davies MJ, Khunti K. The prevalence of co-morbid depression in adults with Type 2 diabetes: a systematic review and meta-analysis. Diabet Med. 2006;23(11):1165-1173.

32. Palinkas LA, Barrett-Connor E, Wingard DL. Type 2 diabetes and depressive symptoms in older adults: a population-based study. Diabet Med. 1991;8(6):532-539.

33. Gonzalez JS, Peyrot M, McCarl LA, Collins EM, Serpa L, Mimiaga MJ, Safren SA. Depression and diabetes treatment nonadherence: a meta-analysis. Diabetes Care. 2008;31(12):2398-2403.

34. de Groot M, Anderson R, Freedland KE, Clouse RE, Lustman PJ. Association of depression and diabetes complications: a meta-analysis. Psychosom Med. 2001;63(4):619630.

35. Egede LE, Zheng D, Simpson K. Comorbid depression is associated with increased health care use and expenditures in individuals with diabetes. Diabetes Care. 2002;25(3):464-470.

36. Park M, Katon WJ, Wolf FM. Depression and risk of mortality in individuals with diabetes: a meta-analysis and systematic review. Gen Hosp Psychiatry. 2013;35(3):217225.

37. Kimbro LB, Mangione CM, Steers WN, Duru OK, McEwen L, Karter A, Ettner SL. Depression and all-cause mortality in persons with diabetes mellitus: are older adults at higher risk? Results from the Translating Research Into Action for Diabetes Study. J Am Geriatr Soc. 2014;62(6):1017-1022.

38. Mezuk B, Eaton WW, Albrecht S, Golden SH. Depression and type 2 diabetes over the lifespan: a meta-analysis. Diabetes Care. 2008;31(12):2383-2390.

39. Anastasiades MH, Gupton OA, Fritz A, Caldaza PJ, Stillman MA. Diabetes, depression and nonadherence: exploring hopelessness as a meditating factor: a preliminary study. Ment Health Fam Med. 2016;12:243-249.

40. DiMatteo MR. Enhancing patient adherence to medical recommendations. JAMA. 1994;271(1):79, 83.

41. Epstein LH, Cluss PA. A behavioral medicine perspective on adherence to long-term medical regimens. J Consult Clin Psychol. 1982;50(6):950-971.

42. Huang CJ, Chiu HC, Lee MH, Wang SY. Prevalence and incidence of anxiety disorders in diabetic patients: a national population-based cohort study. Gen Hosp Psychiatry. 2011;33(1):8-15.

43. Grigsby $A B$, Anderson RJ, Freedland KE, Clouse RE, Lustman PJ. Prevalence of anxiety in adults with diabetes: a systematic review. J Psychosom Res. 2002;53(6):10531060.

44. Tolin DF, Robison JT, Gaztambide S, Blank K. Anxiety disorders in older Puerto Rican primary care patients. Am J Geriatr Psychiatry. 2005;13(2):150-156.

45. Sundbom LT, Bingefors K. The influence of symptoms of anxiety and depression on medication nonadherence and its causes: a population based survey of prescription drug users in Sweden. Patient Prefer Adherence. 2013;7:805811.

46. Shaban MC, Fosbury J, Kerr D, Cavan DA. The prevalence of depression and anxiety in adults with Type 1 diabetes. Diabet Med. 2006;23(12):1381-1384.

47. Hermanns N, Kulzer B, Krichbaum M, Kubiak T, Haak T. Affective and anxiety disorders in a German sample of diabetic patients: prevalence, comorbidity and risk factors. Diabet Med. 2005;22(3):293-300.

48. Snoek FJ, Bremmer MA, Hermanns N. Constructs of depression and distress in diabetes: time for an appraisal. Lancet Diabetes Endocrinol. 2015;3(6):450-460.

49. Gudala K, Bansal D, Schifano F, Bhansali A. Diabetes mellitus and risk of dementia: A meta-analysis of prospective observational studies. J Diabetes Investig. 2013;4(6):640-650.

50. Cukierman T, Gerstein HC, Williamson JD. Cognitive decline and dementia in diabetes - systematic overview of prospective observational studies. Diabetologia. 2005;48(12):2460-2469.

51. Ott A, Stolk RP, van Harskamp F, Pols HA, Hofman A, Breteler MM. Diabetes mellitus and the risk of dementia: The Rotterdam Study. Neurology. 1999;53(9):1937-1942.

52. Biessels GJ, Staekenborg S, Brunner E, Brayne C, Scheltens P. Risk of dementia in diabetes mellitus: a systematic review. Lancet Neurol. 2006;5(1):64-74.

53. Brown AF, Mangione CM, Saliba D, Sarkisian CA, California Healthcare Foundation/American Geriatrics Society Panel on Improving Care for Elders with diabetes. Guidelines for improving the care of the older person with diabetes mellitus. J Am Geriatr Soc. 2003;51(5 Suppl Guidelines):S265-280.

54. Shrivastava SR, Shrivastava PS, Ramasamy J. Role of self-care in management of diabetes mellitus. J Diabetes Metab Disord. 2013;12(1):14.

55. Rosen MI, Beauvais JE, Rigsby MO, Salahi JT, Ryan CE, Cramer JA. Neuropsychological correlates of suboptimal adherence to metformin. J Behav Med. 2003;26(4):349360.

56. Kazlauskaite R, Soni S, Evans AT, Graham K, Fisher B. Accuracy of self-monitored blood glucose in type 2 diabetes. Diabetes Technol Ther. 2009;11(6):385-392.

57. Feil DG, Pearman A, Victor T, Harwood D, Weinreb J, Kahle K, Unutzer J. The role of cognitive impairment and caregiver support in diabetes management of older outpatients. Int J Psychiatry Med. 2009;39(2):199-214.

58. Hewitt J, Smeeth L, Chaturvedi N, Bulpitt CJ, Fletcher AE. Self management and patient understanding of diabetes in the older person. Diabet Med. 2011;28(1):117122.

59. Sinclair AJ, Girling AJ, Bayer AJ. Cognitive dysfunction in older subjects with diabetes mellitus: impact on diabetes self-management and use of care services. All Wales Research into Elderly (AWARE) Study. Diabetes Res Clin Pract. 2000;50(3):203-212.

60. American Diabetes A. Diagnosis and classification of diabetes mellitus. Diabetes Care. 2010;33(Suppl 1):S62-69.

61. Graffar M. Une methode de classification sociale 
d'echantillons de population. Courrier. 1956;6(8):455459.

62. Amaro F. A Classificacao das Familias segundo a Escala de Graffar. Lisboa: Fundacao Nossa Senhora do Bom Sucesso, 2001.

63. Charlson M, Szatrowski TP, Peterson J, Gold J. Validation of a combined comorbidity index. J Clin Epidemiol. 1994;47(11):1245-1251.

64. World Health Organization (WHO). Body mass index - BMI. Available at: http://www.euro.who.int/en/healthtopics/disease-prevention/nutrition/a-healthy-lifestyle/ body-mass-index-bmi Accessed January 2019.

65. Folstein MF, Folstein SE, McHugh PR. "Mini-mental state": A practical method for grading the cognitive state of patients for the clinician. J Psychiatr Res. 1975;12(3):189-198.

66. Guerreiro M, Silva AP, Botelho M, Leitao O, CastroCaldas A, Garcia C. Adaptacao a populacao portuguesa da traducao do Mini Mental State Examination. Rev Port Neurol. 1994;1:9.

67. Zigmond AS, Snaith RP. The hospital anxiety and depression scale. Acta Psychiatr Scand. 1983;67(6):361-370.

68. Pais-Ribeiro J, Silva I, Ferreira T, Martins A, Meneses R, Baltar M. Validation study of a Portuguese version of the Hospital Anxiety and Depression Scale. Psychol Health Med. 2007;12(2):225-235; quiz 235-227.

69. Delgado AB, Lima ML. Contributo para a validacao concorrente de uma medida de adesao aos tratamentos. Psicol. Saude Doenças. 2001;2(2):81-100.

70. Cavanagh P, Evans J, Fiatarone M, Hagberg J, McAuley E, Startzell J. Exercise and physical activity for older adults. Med Sci Sports Exerc. 1998;30(6):1-29.

71. Christmas C, Andersen RA. Exercise and older patients: guidelines for the clinician. J Am Geriatr Soc. 2000;48(3):318-324.

72. Caughey GE, Roughead EE, Vitry AI, McDermott RA, Shakib S, Gilbert AL. Comorbidity in the elderly with diabetes: Identification of areas of potential treatment conflicts. Diabetes Res Clin Pract. 2010;87(3):385-393.

73. Masmoudi J, Damak R, Zouari H, Ouali U, Mechri A, Zouari N, Jaoua A. Prevalence and impact of anxiety and depression on type 2 diabetes in Tunisian patients over sixty years old. Depress Res Treat. 2013;2013:341782.

74. Amiri S, Behnezhad S. Diabetes and anxiety symptoms: A systematic review and meta-analysis. Int J Psychiatry Med. 2019:91217419837407.

75. Chou KL, Chi I. Prevalence of depression among elderly Chinese with diabetes. Int J Geriatr Psychiatry. 2005;20(6):570-575.

76. Chew BH, Shariff-Ghazali S, Fernandez A. Psychological aspects of diabetes care: Effecting behavioral change in patients. World J Diabetes. 2014;5(6):796-808.

77. Penckofer S, Ferrans CE, Velsor-Friedrich B, Savoy S. The psychological impact of living with diabetes: women's day-to-day experiences. Diabetes Educ. 2007;33(4):680690.

78. Ryan CM. Psychological factors and diabetes mellitus. In: Pickup J, Williams G, eds. Textbook of Diabetes. Oxford: Blackwell Science, 1997:66.1-66.13.
79. Fisher EB, Jr., Delamater AM, Bertelson AD, Kirkley BG. Psychological factors in diabetes and its treatment. J Consult Clin Psychol. 1982;50(6):993-1003.

80. Lustman PJ, Anderson RJ, Freedland KE, de Groot M, Carney RM, Clouse RE. Depression and poor glycemic control: a meta-analytic review of the literature. Diabetes Care. 2000;23(7):934-942.

81. Krousel-Wood MA, Muntner P, Islam T, Morisky DE, Webber LS. Barriers to and determinants of medication adherence in hypertension management: perspective of the cohort study of medication adherence among older adults. Med Clin North Am. 2009;93(3):753-769.

82. Turner AP, Pickup JC. Diabetes mellitus: biosensors for research and management. Biosensors. 1985;1(1):85-115.

83. Balhara YP. Diabetes and psychiatric disorders. Indian J Endocrinol Metab. 2011;15(4):274-283.

84. Moreira RO, Papelbaum M, Appolinario JC, Matos AG, Coutinho WF, Meirelles RM, Ellinger V, et al. Diabetes mellitus e depressao: uma revisao sistematica. Arq Bras Endocrinol Metab. 2003;47(1):19-29.

85. Golden SH, Lazo M, Carnethon M, Bertoni AG, Schreiner PJ, Diez Roux AV, Lee HB, et al. Examining a bidirectional association between depressive symptoms and diabetes. JAMA. 2008;299(23):2751-2759.

86. Larkin ME, Capasso VA, Chen CL, Mahoney EK, Hazard B, Cagliero E, Nathan DM. Measuring psychological insulin resistance: barriers to insulin use. Diabetes Educ. 2008;34(3):511-517.

87. Polonsky WH, Anderson BJ, Lohrer PA, Welch G, Jacobson AM, Aponte JE, Schwartz CE. Assessment of diabetes-related distress. Diabetes Care. 1995;18(6):754-760.

88. Peyrot M, McMurry JF, Jr., Kruger DF. A biopsychosocial model of glycemic control in diabetes: stress, coping and regimen adherence. J Health Soc Behav. 1999;40(2):141158.

89. Ciechanowski PS, Katon WJ, Russo JE. Depression and diabetes: impact of depressive symptoms on adherence, function, and costs. Arch Intern Med. 2000;160(21):32783285.

90. Anderson RJ, Grigsby AB, Freedland KE, de Groot M, McGill JB, Clouse RE, Lustman PJ. Anxiety and poor glycemic control: a meta-analytic review of the literature. Int J Psychiatry Med. 2002;32(3):235-247.

91. Brennan C, Harkins V, Perry IJ. Management of diabetes in primary care: a structured-care approach. Eur J Gen Pract. 2008;14(3-4):117-122.

92. Bickett A, Tapp H. Anxiety and diabetes: Innovative approaches to management in primary care. Exp Biol Med (Maywood). 2016;241(15):1724-1731.

93. Bandura A. Self-efficacy. In: Ramachaudran VS, ed. Encyclopedia of human behavior. New York: Academic Press, 1994.

94. Schoenthaler A, Ogedegbe G, Allegrante JP. Self-efficacy mediates the relationship between depressive symptoms and medication adherence among hypertensive African Americans. Health Educ Behav. 2009;36(1):127-137.

95. Bautista LE, Vera-Cala LM, Colombo C, Smith P. Symptoms of depression and anxiety and adherence to antihypertensive medication. Am J Hypertens. 2012;25(4):505- 
511.

96. Moasheri B, Ahangari H, Norozi E, Shayesteh M. An exploration of coping styles in type 2 diabetic patients and their association with demographic factors. HEHP. 2017;5(4):55-63.

97. Colberg SR, Sigal RJ, Fernhall B, Regensteiner JG, Blissmer BJ, Rubin RR, Chasan-Taber L, et al. Exercise and type 2 diabetes: the American College of Sports Medicine and the American Diabetes Association: joint position statement executive summary. Diabetes Care. 2010;33(12):2692-2696.

98. Knowler WC, Barrett-Connor E, Fowler SE, Hamman RF, Lachin JM, Walker EA, Nathan DM, et al. Reduction in the incidence of type 2 diabetes with lifestyle intervention or metformin. N Engl J Med. 2002;346(6):393-403.

99. Tuomilehto J, Lindstrom J, Eriksson JG, Valle TT, Hamalainen $\mathrm{H}$, Ilanne-Parikka P, Keinanen-Kiukaanniemi S, et al. Prevention of type 2 diabetes mellitus by changes in lifestyle among subjects with impaired glucose tolerance. N Engl J Med. 2001;344(18):1343-1350.

100. Pan XR, Li GW, Hu YH, Wang JX, Yang WY, An ZX, $\mathrm{Hu} \mathrm{ZX}$, et al. Effects of diet and exercise in preventing NIDDM in people with impaired glucose tolerance. The Da Qing IGT and Diabetes Study. Diabetes Care. 1997;20(4):537-544.

101. Castaneda C, Layne JE, Munoz-Orians L, Gordon PL, Walsmith J, Foldvari M, Roubenoff R, et al. A randomized controlled trial of resistance exercise training to improve glycemic control in older adults with type 2 diabetes. Diabetes Care. 2002;25(12):2335-2341.

102. Ronnemaa T, Mattila K, Lehtonen A, Kallio V. A controlled randomized study on the effect of long-term physical exercise on the metabolic control in type 2 diabetic patients. Acta Med Scand. 1986;220(3):219-224.

103. Morrato EH, Hill JO, Wyatt HR, Ghushchyan V, Sullivan PW. Physical activity in U.S. adults with diabetes and at risk for developing diabetes, 2003. Diabetes Care. 2007;30(2):203-209.

104. Egede LE, Zheng D. Modifiable cardiovascular risk factors in adults with diabetes: prevalence and missed opportunities for physician counseling. Arch Intern Med. 2002;162(4):427-433.

105. Ford ES, Herman WH. Leisure-time physical activity patterns in the U.S. diabetic population. Findings from the 1990 national health interview survey - health promotion and disease prevention supplement. Diabetes Care. $1995 ; 18(1): 27-33$.

106. Thomas N, Alder E, Leese GP. Barriers to physical activity in patients with diabetes. Postgrad Med J. 2004;80(943):287-291.

107. Rhodes RE, Martin AD, Taunton JE, Rhodes EC, Donnelly M, Elliot J. Factors associated with exercise adherence among older adults. An individual perspective. Sports Med. 1999;28(6):397-411. 